\title{
Conflicting clinical and radiological management decisions
}

\author{
Tamer Zaalouk ${ }^{1}$, zouheir Bitar ${ }^{1}$, and Osama Maadarani ${ }^{1}$ \\ ${ }^{1}$ Ahmadi Hospital
}

August 11, 2020

\begin{abstract}
Gliosis with haemorrhagic transformation is a late reported complication of stroke (1-2), Sometimes there is a big discrepancy between clinical and radiological diagnosis, Clinical decision must be multi-aspects decision and does not depend on a single unusual investigation.
\end{abstract}

\section{Conflicting clinical and radiological management decisions}

Tamer Mohamed Zaalouk*, Zouheir Ibrahim Bitar, Ossama Sajeh Maadarani.

Critical Care Unit, Ahmadi Hospital, Kuwait Oil Company P.O.Box 46468 , Postal code 64015 Fahaheel

Corresponding author.Email: tzaalouk@hkockw.com or forevertn@hotmail.com

\section{KEY CLINICAL MESSAGE}

Gliosis with haemorrhagic transformation is a late reported complication of stroke (1-2), Sometimes there is a big discrepancy between clinical and radiological diagnosis, Clinical decision must be multi-aspects decision and does not depend on a single unusual investigation.

\section{QUESTIONS AND TEXT}

Q1 What is your diagnosis for this CT and MRI images?

Q2 What is your plan of management?

A 48-year-old Asian male with history of ischemic cardiomyopathy with low Ejection fraction (EF 15\%). Received thrombolysis 2 months ago due to Right middle cerebral artery stroke. Presented with low cardiac output state require vasopressors support. Follow up CT brain after 2 month of thrombolysis show (Fig 1-2) multiple hypodense areas with Haemorrhagic transformation and mass effect, MRI confirm gliosis with secondry haemorrhagic transformation and mass effect (Fig 3-4). Neurosurgeon Decision based on only reviewing CT and MRI images was for urgent dehydrating measures and to be refered to the neurosurgery centre for decompressive craniotomy. Surprising the patient was fully concious, alert and oriented with left haemiplegia. Even with no dehydrating measures patient remain stable with same concious level.

\section{AKNOWLEDGMENTS}

No relevant acknowledgments.

\section{CONFLICT OF INTEREST}

Not declared.

\section{AUTHOR CONTRIBUTIONS}


Tamer Zaalouk and Osama Maadarani collected the information, drafted the manuscript and Zohier Bitar revised and approve the final manuscript.

\section{CONSENT}

Informed consent was obtained from the patient for the publication of this clinical image.

\section{FUNDING}

The authors received no financial support for the research, authorship, and/or publication of this article. This research was performed as part of authors duties in kuwait oil Company, kuwait.

\section{REFERENCES}

1. Fawcett, James W; Asher, Richard.A (1999). "The glial scar and central nervous system repair". Brain Research Bulletin . 49 (6): 377-91. doi:10.1016/S0361-9230(99)00072-6. PMID 10483914.

2. Streit, Wolfgang J; Walter, Sharon A; Pennell, Nathan A (1999). "Reactive microgliosis". Progress in Neurobiology . 57 (6): 563-81. doi:10.1016/S0301-0082(98)00069-0. PMID 10221782

\section{Hosted file}

Figures.docx available at https://authorea.com/users/349297/articles/474965-conflictingclinical-and-radiological-management-decisions 